Tôhoku Math. Journ.

39 (1987), 41-59.

\title{
LUSIN FUNCTIONS ON PRODUCT SPACES
}

\author{
ShUICHI SATo
}

(Received January 20, 1986)

1. Introduction. In [1] and [2], Calderón and Torchinsky introduced the parabolic $H^{p}$ spaces associated with a group of linear transformations of $\boldsymbol{R}^{d}$ and obtained analogues of some results of Fefferman-Stein [8] in this context. Later Gundy-Stein [11] extended some of the results of [8] to the product spaces. (See also Gundy [10], M. P. and P. Malliavin [13].) On the other hand, it seems likely that some parts of the theory of Calderón-Torchinsky [1], [2] also extend to the product spaces. In fact, in the present note we prove the equivalence with respect to the $L^{p_{-}}$ "norms" of the Lusin functions and the nontangential maximal functions arising from certain two-parameter families of linear transformations of $\boldsymbol{R}^{n_{1}} \times \boldsymbol{R}^{n_{2}}$ (see Theorem 1 and the corollary in $\S 3$ ), which is an extension to the product spaces of a special case of a result of [1] and also is a generalization of a result of Gundy-Stein [11]. Combined with the argument of Fefferman-Stein [9], this enables us to extend Fefferman's weak type estimates (see [7]) to the case of the double singular integrals with mixed homogeneity (see Theorem 3 in $\S 3$ ).

\section{Preliminaries.}

2.1. Let $x \in \boldsymbol{R}^{n}(n \geqq 2)$. We write $x=\left(x^{(1)}, x^{(2)}\right)$, where $x^{(1)} \in \boldsymbol{R}^{n_{1}}$, $x^{(2)} \in \boldsymbol{R}^{n_{2}}\left(n_{1}, n_{2} \geqq 1, n_{1}+n_{2}=n\right)$ and $x^{(i)}=\left(x_{1}^{(i)}, \cdots, x_{n_{i}}^{(i)}\right)(i=1,2)$. If $X \in \boldsymbol{R}^{n_{1}+1} \times \boldsymbol{R}^{n_{2}+1}$, we write $X=\left(x^{(1)}, t_{1} ; x^{(2)}, t_{2}\right) ; x^{(i)} \in \boldsymbol{R}^{n_{i}}, t_{i} \in \boldsymbol{R}$. (We often write, for example, " $x^{(i)} \in \boldsymbol{R}^{n_{i}}$ " instead of " $x^{(1)} \in \boldsymbol{R}^{n_{1}}$ and $x^{(2)} \in \boldsymbol{R}^{n_{2}}$ " for simplicity. This abbreviation will be used throughout.) We also write $\left(x^{(1)}, t_{1} ; x^{(2)}, t_{2}\right)=(x, t)$, where $x=\left(x^{(1)}, x^{(2)}\right), t=\left(t_{1}, t_{2}\right)$.

Set $\boldsymbol{R}_{+}^{n_{i}+1}=\left\{\left(x^{(i)}, t_{i}\right) \in \boldsymbol{R}^{n_{i}+1}: t_{i}>0\right\}(i=1,2)$ and $\boldsymbol{D}=\boldsymbol{R}_{+}^{n_{1}+1} \times \boldsymbol{R}_{+}^{n_{2}+1}$.

2.2. Let $P_{i}$ be a linear transformation of $\boldsymbol{R}^{n_{i}}$ such that $\left(P_{i} x^{(i)}, x^{(i)}\right) \geqq$ $\left(x^{(i)}, x^{(i)}\right)$ for all $x^{(i)} \in \boldsymbol{R}^{n_{i}}$, where $\left(x^{(i)}, y^{(i)}\right)$ denotes the ordinary inner product in $\boldsymbol{R}^{n_{i}}$. We consider a group $A_{t_{i}}^{(i)}=t_{i}^{P_{i}}\left(0<t_{i}<\infty\right)$ of linear transformations of $\boldsymbol{R}^{n_{i}}$.

For $x^{(i)} \in \boldsymbol{R}^{n_{i}}-\{0\}$, let us denote by $\rho^{(i)}\left(x^{(i)}\right)$ the unique $t_{i}$ such that

Partly supported by the Grants-in-Aid for Encouragement of Young Scientists, The Ministry of Education, Science and Culture, Japan. 
$\left|A_{t_{i}}^{(i)-1} x^{(i)}\right|=1$, where $\left|x^{(i)}\right|=\left(x^{(i)}, x^{(i)}\right)^{1 / 2}$, and we define $\rho^{(i)}(0)=0 . \quad \rho^{(i) *}$ is defined similarly in terms of $A_{t_{i}}^{(i) *}$, where $A_{t_{i}}^{(i) *}$ is the transposed transformation of $A_{t_{i}}^{(i)}$.

2.3. Let $f^{(1)}$ and $f^{(2)}$ be functions defined on $\boldsymbol{R}^{n_{1}}$ and $\boldsymbol{R}^{n_{2}}$, respectively. We define a function $f^{(1)} \times f^{(2)}$ on $\boldsymbol{R}^{n}$ by

$$
\left(f^{(1)} \times f^{(2)}\right)\left(x^{(1)}, x^{(2)}\right)=f^{(1)}\left(x^{(1)}\right) f^{(2)}\left(x^{(2)}\right) \text {. }
$$

An operator $T_{t_{i}}^{(i)}\left(t_{i}>0\right)$ is defined by

$$
T_{t_{i}}^{(i)} f^{(i)}\left(x^{(i)}\right)=f^{(i)}\left(A_{t_{i}}^{(i)} x^{(i)}\right)
$$

We set

$$
f_{t_{i}}^{(i)}\left(x^{(i)}\right)=t_{i}^{-\gamma_{i}}\left(T_{t_{i}}^{(i)-1} f^{(i)}\right)\left(x^{(i)}\right)=t_{i}^{-\gamma_{i}} f^{(i)}\left(A_{t_{i}}^{(i)-1} x^{(i)}\right),
$$

where $\gamma_{i}=\operatorname{trace} P_{i}$,

Set

$$
\begin{gathered}
A_{\left(t_{1}, t_{2}\right)}\left(x^{(1)}, x^{(2)}\right)=\left(A_{t_{1}}^{(1)} x^{(1)}, A_{t_{2}}^{(2)} x^{(2)}\right), \\
A_{\left(t_{1}, t_{2}\right)}^{*}\left(\xi^{(1)}, \xi^{(2)}\right)=\left(A_{t_{1}}^{(1) *} \xi^{(1)}, A_{t_{2}}^{(2) *} \xi^{(2)}\right) .
\end{gathered}
$$

If $f$ is a function on $\boldsymbol{R}^{n}$, an operator $T_{t}$ is defined by

$$
T_{t} f(x)=f\left(A_{t} x\right) \text {. }
$$

We set

$$
f_{t}(x)=t_{1}^{-\gamma_{1}} t_{2}^{-\gamma_{2}}\left(T_{t}^{-1} f\right)(x)=t_{1}^{-\gamma_{1}} t_{2}^{-\gamma_{2}} f\left(A_{t_{1}}^{(1)-1} x^{(1)}, A_{t_{2}}^{(2)-1} x^{(2)}\right) .
$$

2.4. There is a unique strictly positive self-adjoint transformation $B_{i}$ of $\boldsymbol{R}^{n_{i}}$ such that $P_{i} B_{i}+B_{i} P_{i}^{*}=I_{i}$, where $I_{i}$ is the identity transformation of $\boldsymbol{R}^{n_{i}}$.

Let $G^{(i)}$ be the inverse Fourier transform of the function $\exp \left(-4 \pi^{2}\left(B_{i} \xi^{(i)}, \xi^{(i)}\right)\right)$. (If $f^{(j)} \in L^{1}\left(\boldsymbol{R}^{n_{j}}\right)(j=1,2)$, the Fourier transform of $f^{(j)}$ is defined by $\hat{f}^{(j)}\left(\xi^{(j)}\right)=\int f^{(j)}\left(x^{(j)}\right) e^{-2 \pi i\left(x^{(j)}, \xi^{(j))}\right.} d x^{(j)}$.) Set $G=G^{(1)} \times G^{(2)}$, $G^{(j, k)}=\left(\partial_{j}^{(1)} G^{(1)}\right) \times\left(\partial_{k}^{(2)} G^{(2)}\right)$, where $\partial_{j}^{(i)}=\partial / \partial x_{j}^{(i)}\left(j=1, \cdots, n_{i}\right)$.

2.5. If $a_{i}>0$, set

$$
\Gamma_{a_{i}}^{(i)}\left(x^{(i)}\right)=\left\{\left(y^{(i)}, t_{i}\right) \in \boldsymbol{R}_{+}^{n_{i}+1}: \rho^{(i)}\left(x^{(i)}-y^{(i)}\right)<a_{i} t_{i}\right\},
$$

and for $a=\left(a_{1}, a_{2}\right)$ set

$$
\Gamma_{a}(x)=\Gamma_{a_{1}}^{(1)}\left(x^{(1)}\right) \times \Gamma_{a_{2}}^{(2)}\left(x^{(2)}\right)=\left\{\left(y^{(1)}, t_{1} ; y^{(2)}, t_{2}\right):\left(y^{(i)}, t_{i}\right) \in \Gamma_{a_{i}}^{(i)}\left(x^{(i)}\right)(i=1,2)\right\} .
$$

If $F^{(i)}$ is a function on $\boldsymbol{R}_{+}^{n_{+}+1}$, we define the nontangential maximal function by

$$
N_{a_{i}}^{(i)}\left(F^{(i)}\right)\left(x^{(i)}\right)=\sup \left\{\left|F^{(i)}\left(y^{(i)}, t_{i}\right)\right|:\left(y^{(i)}, t_{i}\right) \in \Gamma_{a_{i}}^{(i)}\left(x^{(i)}\right)\right\}
$$


and the Lusin function by

$$
S_{a_{i}}^{(i)}\left(F^{(i)}\right)\left(x^{(i)}\right)=\left(\int_{\Gamma_{a_{i}}^{(i)}\left(x^{(i))}\right.}\left|F^{(i)}\left(y^{(i)}, t_{i}\right)\right|^{2} t_{i}^{-\gamma_{i}} d y^{(i)} \frac{d t_{i}}{t_{i}}\right)^{1 / 2} .
$$

For a function $F$ on $\boldsymbol{D}$, we define the nontangential maximal function by

$$
N_{a}(F)(x)=\sup \left\{|F(y, t)|:(y, t) \in \Gamma_{a}(x)\right\},
$$

and the Lusin function by

$$
S_{a}(F)(x)=\left(\int_{\Gamma_{a}(x)}|F(y, t)|^{2} t_{1}^{-\gamma_{1}} t_{2}^{-\gamma_{2}} d y \frac{d t}{t_{1} t_{2}}\right)^{1 / 2} .
$$

Let $\Gamma_{1}^{(i)}=\Gamma^{(i)}, \Gamma_{(1,1)}=\Gamma, N_{1}^{(i)}=N^{(i)}, S_{1}^{(i)}=S^{(i)}, N_{(1,1)}=N$ and $S_{(1,1)}=S$.

For more details about 2.2, 2.3, 2.4 and 2.5 see [1].

2.6. $\mathscr{S}\left(\boldsymbol{R}^{m}\right)$ denotes the Schwartz class of infinitely differentiable and rapidly decreasing functions on $\boldsymbol{R}^{m}$. Let

$$
\begin{aligned}
& \mathscr{S}_{0}\left(\boldsymbol{R}^{n_{i}}\right)=\left\{f \in S\left(\boldsymbol{R}^{n_{i}}\right): \hat{f}(0)=0\right\}, \\
& \mathscr{S}_{1}\left(\boldsymbol{R}^{n_{i}}\right)=\left\{f \in S\left(\boldsymbol{R}^{n_{i}}\right): \hat{f}(0)=1\right\} .
\end{aligned}
$$

$\mathscr{S}^{\prime}\left(\boldsymbol{R}^{m}\right)$ denotes the set of tempered distributions in $\boldsymbol{R}^{m}$. $\mathscr{S}_{*}^{\prime}\left(\boldsymbol{R}^{m}\right)$ denotes the set of tempered distributions $f$ such that $\hat{f}(\xi)\left(1+|\xi|^{2}\right)^{-k} \in$ $L^{2}\left(\boldsymbol{R}^{m}\right)$ for sufficiently large $k$.

2.7. If $E$ is a set, $\chi_{E}$ denotes its characteristic function and $\complement E$ denotes its complement.

The letter $c$ is used to denote a constant which need not be the same at each occurrence.

3. Statement of results. Let $f \in \mathscr{S}^{\prime}\left(\boldsymbol{R}^{n}\right)$ and set $F(x, t)=f * G_{t}(x)$ (cf. 2.3, 2.4), where the symbol $*$ denotes the operation of convolution. We say that $f \in H_{n_{1}, n_{2}}^{p}(0<p<\infty)$ if $N(F) \in L^{p}\left(\boldsymbol{R}^{n}\right)$ and set $\|f\|_{H_{n_{1}, n_{2}}^{p}}=$ $\|N(F)\|_{p}$, where $\|\cdot\|_{p}$ denotes the $L^{p}$-norm.

It is easy to see that $H_{n_{1}, n_{2}}^{p}$ coincides with $L^{p}$ if $p>1$ and $H_{1,1}^{p}(0<$ $p<\infty)$ is independent of $P_{i}$.

Certain $H_{n_{1}, n_{2}}^{p}$ spaces are characterized in terms of the Lusin functions as we show in Theorem 1 and Corollary below.

TheOREM 1. Let $\phi^{(i)} \in \mathscr{S}_{1}\left(\boldsymbol{R}^{n_{i}}\right)$ and $\psi_{j}^{(i)} \in \mathscr{S}_{0}\left(\boldsymbol{R}^{n_{i}}\right)\left(j=1, \cdots, l_{i}\right)$. Suppose that

$$
\sup _{t_{i}>0} \sum_{j=1}^{l_{i}}\left|\hat{\psi}_{j}^{(i)}\left(A_{t_{i}}^{(i) *} \xi^{(i)}\right)\right|>0 \quad \text { if } \quad \xi^{(i)} \neq 0
$$

Set $\phi=\phi^{(1)} \times \phi^{(2)}, \psi^{(j, k)}=\psi_{j}^{(1)} \times \psi_{k}^{(2)}$, and $F(x, t)=f * \phi_{t}(x), K_{j k}(x, t)=f *$ 
$\psi_{t}^{(j, k)}(x)$ for $f \in \mathscr{S}_{*}^{\prime}\left(\boldsymbol{R}^{n}\right)$. Then if $1<p<2$, or if $0<p \leqq 1$ and $P_{i}$ is diagonal, we have

$$
\|N(F)\|_{p} \leqq c \sum_{j=1}^{l_{1}} \sum_{k=1}^{l_{2}}\left\|S\left(K_{j k}\right)\right\|_{p} .
$$

REmark. This result also holds when $p \geqq 2$ and $f \in L^{p}$ by a duality argument and the results below.

THEOREM 2. If $f \in \mathscr{S}_{*}^{\prime}\left(\boldsymbol{R}^{n}\right)$, set $F(x, t)=f * G_{t}(x)$ and $K_{j k}(x, t)=f *$ $G_{t}^{(j, k)}(x)$. Then

$$
\left|\left\{x: S\left(\left(\sum_{j=1}^{n_{1}} \sum_{k=1}^{n_{2}}\left|K_{j k}\right|^{2}\right)^{1 / 2}\right)(x)>1\right\}\right| \leqq c \int_{R^{n}}\{N(F) \wedge 1\}^{2} d x,
$$

where the symbol $\wedge$ denotes the operation of taking the minimum.

We will prove this by the idea of [11] and [13].

CoRollaRY. Let $\phi^{(i)} \in \mathscr{S}_{1}\left(\boldsymbol{R}^{n_{i}}\right)$ and $\psi^{(i)} \in \mathscr{S}_{0}\left(\boldsymbol{R}^{n_{i}}\right)$. Set $\phi=\phi^{(1)} \times \phi^{(2)}$, $\psi=\psi^{(1)} \times \psi^{(2)}$, and $F(x, t)=f * \phi_{t}(x), K(x, t)=f * \psi_{t}(x)$ for $f \in \mathscr{S}^{\prime}\left(\boldsymbol{R}^{n}\right)$. Then

$$
\|S(K)\|_{p} \leqq c\|N(F)\|_{p} \quad(0<p<2) .
$$

This follows immediately from Theorem 2 and Lemmas 4 and 5 in $\S 4$ (See [1, Lemma 3.3]).

REMARK. The corollary also holds when $p \geqq 2$ as a consequence of the theory of singular integrals.

We give an application of the above results. Let $K^{(i)} \in C^{\infty}\left(\boldsymbol{R}^{n_{i}}-\{0\}\right)$ be such that

$$
\begin{gathered}
\int_{\mid x^{(i) \mid}=1} K^{(i)}\left(x^{(i)}\right)\left(P_{i} x^{(i)}, x^{(i)}\right) d \sigma\left(x^{(i)}\right)=0, \\
K^{(i)}\left(A_{t_{i}}^{(i)} x^{(i)}\right)=t_{i}^{-\gamma_{i}} K^{(i)}\left(x^{(i)}\right) \text { for all } t_{i}>0,
\end{gathered}
$$

where $d \sigma\left(x^{(i)}\right)$ is the area element of $S^{n_{i}-1}=\left\{x^{(i)}:\left|x^{(i)}\right|=1\right\}$. (See [6], [14].) Set

$$
K_{\varepsilon_{1}, \varepsilon_{2}}\left(x^{(1)}, x^{(2)}\right)=\prod_{i=1,2} K^{(i)}\left(x^{(i)}\right)\left(1-\chi_{[0,1]}\left(\varepsilon_{i}^{-1} \rho^{(i)}\left(x^{(i)}\right)\right)\right) \text { for } \varepsilon_{1}, \varepsilon_{2}>0 .
$$

TheOREm 3. Suppose $P_{i}$ is diagonal. Let $A$ and $B$ be compact sets in $\boldsymbol{R}^{n}$. If $f$ is a function on $\boldsymbol{R}^{n}$ vanishing outside $B$ and if $\int_{B}|f| \log (2+|f|) d x<\infty$, then we have

$$
\left|\left\{x \in A: \sup _{\varepsilon_{1}, \varepsilon_{2}>0}\left|f * K_{\varepsilon_{1}, \varepsilon_{2}}(x)\right|>1\right\}\right| \leqq c \int_{B}|f| \log (2+|f|) d x .
$$

This is a generalization of the weak type estimates of [7]. 
4. Lemmas. In this section, we give several lemmas, which will be used in the proof of Theorem 1. We prove Lemmas 1, 2 and 4 in later sections.

Let $u_{1}^{(i)}\left(s_{i}\right)=s_{i}\left(s_{i}>0\right)$ and let $u_{j}^{(i)}\left(s_{i}\right) \quad\left(j=2, \cdots, n_{i}\right)$ be positive increasing functions. Set

$$
\Gamma^{i}=\left\{\xi^{(i)}:\left|\xi_{2}^{(i)}\right| \leqq u_{2}^{(i)}\left(\xi_{1}^{(i)}\right), \cdots,\left|\xi_{n_{i}}^{(i)}\right| \leqq u_{n_{i}}^{(i)}\left(\xi_{1}^{(i)}\right), \xi_{1}^{(i)}>0\right\}
$$

and

$$
\Gamma_{0}=\Gamma^{1} \times \Gamma^{2}=\left\{\left(\xi^{(1)}, \xi^{(2)}\right): \xi^{(1)} \in \Gamma^{1}, \xi^{(2)} \in \Gamma^{2}\right\} .
$$

LEMma 1. There is $\Phi^{(i)} \in \mathscr{S}_{1}\left(\boldsymbol{R}^{n_{i}}\right)$ such that if we denote by $\Phi_{s_{1}, s_{2}}(x)$ the function:

$$
\prod_{i=1,2} u_{1}^{(i)}\left(s_{i}\right) \cdots u_{n_{i}}^{(i)}\left(s_{i}\right) \Phi^{(i)}\left(u_{1}^{(i)}\left(s_{i}\right) x_{1}^{(i)}, \cdots, u_{n_{i}}^{(i)}\left(s_{i}\right) x_{n_{i}}^{(i)}\right),
$$

then

$$
\left\|\sup _{s_{1}, s_{2}>0}\left|f * \Phi_{s_{1}, s_{2}}\right|\right\|_{p} \leqq c\|f\|_{p}
$$

$(0<p<\infty)$ for all $f \in L^{2}\left(\boldsymbol{R}^{n}\right)$ with $\hat{f}$ vanishing outside $\Gamma_{0}$.

This is an analogue of Coifman-Dahlberg [4, Theorem I]. (See also Carleson [3] and Coifman-Weiss [5, p. 585].) that

Let $\left\{\omega_{j}^{(i)}: j=1, \cdots, 2 n_{i}\right\}$ be a $C^{\infty}$-partition of unity on $\boldsymbol{R}^{n_{i}}-\{0\}$ such

$$
\begin{aligned}
& \mathrm{Cl}\left\{\xi^{(i)}: \omega_{j}^{(i)}\left(\xi^{(i)}\right) \neq 0,\left|\xi^{(i)}\right|=1\right\} \subset\left\{\xi^{(i)}: \xi_{j}^{(i)}>0,\left|\xi^{(i)}\right|=1\right\} \\
& \left.\mathrm{Cl}\left\{\xi^{(i)}: \omega_{n_{i}+j}^{(i)}\left(\xi^{(i)}\right) \neq 0, \mid \xi^{(i)}\right\}=1\right\} \subset\left\{\xi^{(i)}: \xi_{j}^{(i)}<0,\left|\xi^{(i)}\right|=1\right\}
\end{aligned}
$$

for $j=1, \cdots, n_{i}$ (where for a set $E, \mathrm{Cl} E$ denotes its closure) and such that $\omega_{j}^{(i)}\left(\xi^{(i)}\right)=\omega_{j}^{(i)}\left(A_{t_{i}}^{(i) *} \xi^{(i)}\right)$ for all $t_{i}>0$. Define an operator $T_{j k}$ by

$$
\left(T_{j k} f\right)^{\wedge}(\xi)=\omega_{j}^{(1)}\left(\xi^{(1)}\right) \omega_{k}^{(2)}\left(\xi^{(2)}\right) \hat{f}(\xi)
$$

for $f \in L^{2}\left(\boldsymbol{R}^{n}\right)$.

Lemma 2. Let $\phi^{(i)} \in \mathscr{S}_{1}\left(\boldsymbol{R}^{n_{i}}\right)$ and set $\phi=\phi^{(1)} \times \phi^{(2)}$. Suppose that $P_{i}$ is diagonal. Then

$$
\left\|\sup _{t}\left|f * \phi_{t}\right|\right\|_{p} \leqq c \sum_{j=1}^{2 n_{1}} \sum_{k=1}^{2 n_{2}}\left\|T_{j k} f\right\|_{p}
$$

for $0<p<\infty$.

This is a consequence of Lemma 1 .

Let $W$ be a measurable subset of $\boldsymbol{R}^{m}$ and $\omega$ be a positive function on $W$. Let $\phi^{(1)} \in \mathscr{S}_{1}\left(\boldsymbol{R}^{n_{1}}\right)$ and $\psi^{(1)} \in \mathscr{S}_{0}\left(\boldsymbol{R}^{n_{1}}\right)$ and suppose

$$
\sup _{t_{1}>0}\left|\hat{\psi}^{(1)}\left(A_{t_{1}}^{(1) *} \xi^{(1)}\right)\right|>0 \text { if } \xi^{(1)} \neq 0 .
$$


If $f$ is a function on $\boldsymbol{R}^{n_{1}} \times W=\left\{\left(x^{(1)}, w\right): x^{(1)} \in \boldsymbol{R}^{n_{1}}, w \in W\right\}$ such that

$$
\int_{R^{n_{1} \times W}}\left|f\left(x^{(1)}, w\right)\right|^{2} \omega(w) d x^{(1)} d w<\infty,
$$

then we set

$$
\begin{aligned}
& F\left(y^{(1)}, t_{1} ; w\right)=\int \phi_{t_{1}}^{(1)}\left(y^{(1)}-z^{(1)}\right) f\left(z^{(1)}, w\right) d z^{(1)}, \\
& K\left(y^{(1)}, t_{1} ; w\right)=\int \psi_{t_{1}}^{(1)}\left(y^{(1)}-z^{(1)}\right) f\left(z^{(1)}, w\right) d z^{(1)}
\end{aligned}
$$

LEMMA 3. Set

$$
\begin{aligned}
|F|_{W}\left(y^{(1)}, t_{1}\right) & =\left(\int_{W}\left|F\left(y^{(1)}, t_{1} ; w\right)\right|^{2} \omega(w) d w\right)^{1 / 2}, \\
|K|_{W}\left(y^{(1)}, t_{1}\right) & =\left(\int_{W}\left|K\left(y^{(1)}, t_{1} ; w\right)\right|^{2} \omega(w) d w\right)^{1 / 2} .
\end{aligned}
$$

Then we have

$$
\left\|N^{(1)}\left(|F|_{W}\right)\right\|_{p} \leqq c\left\|S^{(1)}\left(|K|_{W}\right)\right\|_{p} \quad(0<p<2) .
$$

This is a vector-valued analogue of Calderón-Torchinsky [1, Theorem $6.9]$ and can be proved along the same line.

Lemma 4. Let $f \in \mathscr{S}_{*}^{\prime}\left(\boldsymbol{R}^{n}\right), \eta^{(i)} \in \mathscr{S}_{0}\left(\boldsymbol{R}^{n_{i}}\right)$ and let $\psi^{(j, k)}$ be the same as in Theorem 1. Set $L(x, t)=f * \eta_{t}(x)\left(\eta=\eta^{(1)} \times \eta^{(2)}\right), K_{j k}(x, t)=f * \psi_{t}^{(j, k)}(x)$. Then if $0<p \leqq 2$, we have

$$
\left\|S_{a}(L)\right\|_{p} \leqq c \sum_{j, k}\left\|S_{b}\left(K_{j k}\right)\right\|_{p} .
$$

If $F$ is a function on $D$, we set

$$
F^{+}(x)=\sup _{t}|F(x, t)| \text {. }
$$

Lemma 5. Let $f \in \mathscr{S}^{\prime}\left(\boldsymbol{R}^{n}\right)$ and $\phi^{(i)}, \psi^{(i)} \in \mathscr{S}_{1}\left(\boldsymbol{R}^{n_{i}}\right)$. Set $\phi=\phi^{(1)} \times \phi^{(2)}$, $\psi=\psi^{(1)} \times \psi^{(2)}$ and $F(x, t)=f * \phi_{t}(x), H(x, t)=f * \psi t(x)$. Then

$$
\left\|N_{a}(H)\right\|_{p} \leqq c\left\|F^{+}\right\|_{p} \text { for } 0<p<\infty \text {. }
$$

The arguments of [1] and [8] also apply to the proof of Lemma 5.

Let $\lambda=\left(\lambda_{1}, \lambda_{2}\right) ; \lambda_{1}, \lambda_{2}>0$. If $F$ is a function on $D$, we set

$$
G_{\lambda}(F)(x)=\left[\int_{D}|F(y, t)|^{2} \prod_{i=1,2}\left\{\left(1+\frac{\rho^{(i)}\left(x^{(i)}-y^{(i)}\right)}{t_{i}}\right)^{-2 \lambda_{i}} t_{i}^{-\gamma_{i}}\right\} d y \frac{d t}{t_{1} t_{2}}\right]^{1 / 2} .
$$

LEMMA 6. Let $f \in \mathscr{S}_{*}^{\prime}\left(\boldsymbol{R}^{n}\right), \phi^{(i)} \in \mathscr{S}_{0}\left(\boldsymbol{R}^{n_{i}}\right), \eta^{(i)} \in \mathscr{S}\left(\boldsymbol{R}^{n_{i}}\right)$ and let $\phi=$ $\phi^{(1)} \times \phi^{(2)}, \eta=\eta^{(1)} \times \eta^{(2)}, \hat{\psi}=\hat{\phi} \hat{\eta}$. If $k \in L^{\infty}\left(\boldsymbol{R}^{n}\right)$, define Tf by $(T f)^{\wedge}=k \hat{f}$ and $h^{(t)}$ by $\hat{h}^{(t)}(\xi)=\hat{\eta}(\xi) k\left(A_{t}^{*} \xi\right)$. Set $F(x, t)=f * \phi_{t}(x)$ and $H(x, t)=T f *$ $\psi_{t}(x)$. Suppose that $l^{(t)}(x)=h^{(t)}(x) \prod_{i=1,2}\left(1+\rho^{(i)}\left(x^{(i)}\right)\right)^{\lambda_{i}} \quad\left(\lambda_{i}>0\right) \in L^{2}\left(\boldsymbol{R}^{n}\right)$ 
and $\sup _{t}\left\|l^{(t)}\right\|_{2}<\infty$. Then if $\mu=\left(\mu_{1}, \mu_{2}\right), \lambda=\left(\lambda_{1}, \lambda_{2}\right)$ and $\mu_{1}-\lambda_{1}>\gamma_{1} / 2$, $\mu_{2}-\lambda_{2}>\gamma_{2} / 2$, we have

$$
G_{\mu}(H) \leqq c G_{\lambda}(F) \cdot
$$

The proof of Lemma 6 is similar to that of Theorem 5.3 of [1], and is omitted.

5. Proof of Lemma 1. Let $\phi \in \mathscr{S}\left(\boldsymbol{R}^{1}\right)$ be such that

$$
\hat{\phi}(\zeta)=\left\{\begin{array}{lll}
1 & \text { if } & |\zeta| \leqq 1 / 2 \\
0 & \text { if } & |\zeta| \geqq 1
\end{array}\right.
$$

Define $\Phi^{(i)} \in \mathscr{S}\left(\boldsymbol{R}^{n_{i}}\right)$ by

$$
\hat{\Phi}^{(i)}\left(\xi^{(i)}\right)=\hat{\phi}\left(\xi_{1}^{(i)}\right) \hat{\phi}\left(\frac{\xi_{2}^{(i)}}{2}\right) \cdots \hat{\phi}\left(\frac{\xi_{n_{i}}^{(i)}}{2}\right)
$$

and let $\Phi_{s_{1}, s_{2}}$ be the same as in the statement of Lemma 1 .

Suppose that $f \in L^{2}\left(\boldsymbol{R}^{n}\right)$ and $\hat{f}$ vanishes outside $\Gamma_{0}$. Then note that

$$
\hat{\phi}\left(\frac{\xi_{1}^{(1)}}{s_{1}}\right) \hat{\phi}\left(\frac{\xi_{1}^{(2)}}{s_{2}}\right) \hat{f}(\xi)=\hat{\Phi}_{s_{1}, s_{2}}(\xi) \hat{f}(\xi) \text {. }
$$

The proof of Lemma 1 is based on the observation (5.1) and the following lemma.

LEMMA 7. Let $f \in L^{2}\left(\boldsymbol{R}^{2}\right)$ and suppose that supp $\hat{f} \subset \Gamma_{*}=\left\{\left(y_{1}, y_{2}\right) \in \boldsymbol{R}^{2}\right.$ : $\left.y_{1} \geqq 0, y_{2} \geqq 0\right\}$. Then if $f \in L^{p}\left(\boldsymbol{R}^{2}\right)(0<p<\infty)$, it follows that $f \in H_{1,1}^{p}$ and

$$
\|f\|_{H_{1,1}^{p}} \leqq c\|f\|_{L^{p}\left(R^{2}\right)}
$$

(This can be proved by the argument of Stein-Weiss [17, pp. 116-117] and the theory of Fefferman-Stein [8].)

Set $F_{s_{1}, s_{2}}(x)=f * \Phi_{s_{1}, s_{2}}(x)$. If $x^{(1)}=\left(x_{1}^{(1)}, x^{(1) \prime}\right), x^{(2)}=\left(x_{1}^{(2)}, x^{(2) \prime}\right)$ and if we consider $F_{s_{1}, s_{2}}$ and $f$ as functions of $\left(x_{1}^{(1)}, x_{1}^{(2)}\right)$, fixing $x^{(1) \prime}$ and $x^{(2) \prime}$, then we write

$F_{s_{1}, s_{2}}\left(x_{1}^{(1)}, x^{(1) \prime} ; x_{1}^{(2)}, x^{(2)^{\prime}}\right)=\widetilde{F}_{s_{1}, s_{2}}\left(x_{1}^{(1)}, x_{1}^{(2)}\right), \quad f\left(x_{1}^{(1)}, x^{(1) \prime} ; x_{1}^{(2)}, x^{(2) \prime}\right)=\widetilde{f}\left(x_{1}^{(1)}, x_{1}^{(2)}\right)$. and $x^{(2) \prime}$

When $\int\left|F_{s_{1}, s_{2}}(x)\right|^{p} d x<\infty$, by Lemma 7 we have for almost every $x^{(1)}$,

$$
\left\|\sup _{s_{1}, z_{2}>0}\left|\left(\phi_{s_{1}} \times \phi_{s_{2}}\right) * \tilde{f}\right|\right\|_{L^{p}\left(R^{2}\right)} \leqq c\|\tilde{f}\|_{L^{p}\left(R^{2}\right)},
$$

where $\phi_{s_{i}}\left(x_{1}^{(i)}\right)=s_{i} \phi\left(s_{i} x_{1}^{(i)}\right)$.

From (5.1) it follows that

$$
\widetilde{F}_{s_{1}, s_{2}}=\left(\phi_{s_{1}} \times \phi_{s_{2}}\right) * \tilde{f} .
$$


Thus by (5.2) we have

$$
\begin{aligned}
\int_{R^{2}} \sup _{s_{1}, s_{2}>0}\left|\widetilde{F}_{s_{1}, s_{2}}\right| p d x_{1}^{(1)} d x_{1}^{(2)} & =\int_{R^{2}} \sup _{s_{1}, s_{2}>0}\left|\left(\phi_{s_{1}} \times \phi_{s_{2}}\right) * \widetilde{f}\right|^{p} d x_{1}^{(1)} d x_{1}^{(2)} \\
& \leqq c \int_{R^{2}}|\tilde{f}|^{p} d x_{1}^{(1)} d x_{1}^{(2)} .
\end{aligned}
$$

Integrating this with respect to $x^{(1) \prime}$ and $x^{(2)^{\prime}}$, we obtain

$$
\int \sup _{s_{1}, s_{2}>0}\left|F_{s_{1}, s_{2}}(x)\right|^{p} d x \leqq c \int|f|^{p} d x,
$$

which proves Lemma 1.

6. Proof of Lemma 2. If $P_{i}$ is diagonal, then

$$
A_{t_{i}}^{(i) *} \xi^{(i)}=\left(t_{i}^{\alpha} \xi_{1}^{(i)}, \cdots, t_{i}^{\alpha} \hat{n}_{i}^{(i)} \xi_{n_{i}}^{(i)}\right) \text { for some } \alpha_{j}^{(i)} \geqq 1 .
$$

Set

$$
\Gamma_{j}^{i}=\left\{\xi^{(i)}:\left|\xi_{k}^{(i)}\right|^{\alpha_{j}^{(i)}} \leqq c_{0}\left|\xi_{j}^{(i)}\right|^{(i)}\left(1 \leqq k \leqq n_{i}\right), \xi_{j}^{(i)} \geqq 0\right\} \quad \text { for } \quad j=1, \cdots, n_{i}
$$

and

$$
\Gamma_{n_{i}+j}^{i}=\left\{-\xi^{(i)}: \xi^{(i)} \in \Gamma_{j}^{i}\right\} \quad\left(j=1, \cdots, n_{i}\right) .
$$

Since $\operatorname{supp}\left(T_{j k} f\right)^{\wedge} \subset \Gamma_{j}^{1} \times \Gamma_{k}^{2}$ for some $c_{0}>0$, by Lemma 1 there are $\phi_{j}^{(1)} \in$ $\mathscr{S}_{1}\left(\boldsymbol{R}^{n_{1}}\right)$ and $\phi_{k}^{(2)} \in \mathscr{S}_{1}\left(\boldsymbol{R}^{n_{2}}\right)$ such that

$$
\left\|\sup _{t}\left|T_{j k} f * \phi_{t}^{(j, k)}\right|\right\|_{p} \leqq c\left\|T_{j k} f\right\|_{p}
$$

where $\phi^{(j, k)}=\phi_{j}^{(1)} \times \phi_{k}^{(2)}$. Since $\sum_{j, k} T_{j k} f=f$, this, combined with Lemma 5, proves Lemma 2.

7. Proof of Lemma 4. If $F$ is a function on $D$, then clearly we have $S_{a}(F) \leqq c G_{\lambda}(F)$. On the other hand, the following result holds.

LEMMA 8. If $0<p \leqq 2$ and $\lambda=\left(\lambda_{1}, \lambda_{2}\right)$ with $\lambda_{1}>\gamma_{1} / p, \lambda_{2}>\gamma_{2} / p$, then

$$
\left\|G_{\lambda}(F)\right\|_{p} \leqq c\left\|S_{a}(F)\right\|_{p} \text {. }
$$

Thus Lemma 4 follows from the following lemma.

LEMMA 9. Let $L$ and $K_{j k}$ be the same as in Lemma 4. Then if $\lambda=\left(\lambda_{1}, \lambda_{2}\right), \mu=\left(\mu_{1}, \mu_{2}\right)$ with $\mu_{1}-\lambda_{1}>\gamma_{1}$ and $\mu_{2}-\lambda_{2}>\gamma_{2}$, we have

$$
G_{\mu}(L) \leqq c \sum_{j=1}^{l_{1}} \sum_{k=1}^{l_{2}} G_{\lambda}\left(K_{j k}\right) \text {. }
$$

(We can prove Lemma 8 and Lemma 9 by using [1, Theorem 3.5] and [1, Theorem 5.5], respectively.) 
8. Proof of Theorem 1. Let $\eta^{(i)} \in \mathscr{S}\left(\boldsymbol{R}^{n_{i}}\right), \phi^{(i)} \in \mathscr{S}_{1}\left(\boldsymbol{R}^{n_{i}}\right)$ and set $\eta=\eta^{(1)} \times \eta^{(2)}, \phi=\phi^{(1)} \times \phi^{(2)}$. Suppose that

$$
\sup _{t_{i}>0}\left|\hat{\eta}^{(i)}\left(A_{t_{i}}^{(i) *} \xi^{(i)}\right)\right|>0 \quad \text { if } \quad \xi^{(i)} \neq 0
$$

and

$$
\operatorname{supp} \hat{\eta}^{(i)} \subset\left\{\xi^{(i)}: 1 \leqq \rho^{(i) *}\left(\xi^{(i)}\right) \leqq 2\right\} .
$$

To prove the theorem, we first assume that $f \in L^{2}\left(\boldsymbol{R}^{n}\right)$. Set $H(y, t)=$ $f * \eta_{t}(y)$. Then arguing as in [11], by using Lemma 3 , we have

$$
\sup _{t}\left\|f * \phi_{t}\right\|_{p}^{p} \leqq c \int S^{p}(H) d x .
$$

This proves the theorem when $p>1$. When $0<p \leqq 1$, suppose that $P_{i}$ is diagonal, and let $T_{j k}$ be the same as in Lemma 2. Then by Lemma 2 and (8.1)

$$
\left\|\sup _{t} \mid f * \phi_{t}\right\|\left\|_{p}^{p} \leqq c \sum_{j, k}\right\| T_{j k} f \|_{p}^{p} \leqq c \sum_{j, k} \int S^{p}\left(L_{j k}\right) d x,
$$

where $L_{j k}(y, t)=T_{j k} f * \eta_{t}(y)$. Note that $L_{j k}(y, t)=f * \theta_{t}^{(j, k)}(y)$ for some $\theta^{(j, k)}=\theta_{j}^{(1)} \times \theta_{k}^{(2)} \quad$ with $\theta_{j}^{(1)} \in \mathscr{S}_{0}\left(\boldsymbol{R}^{n_{1}}\right)$ and $\theta_{k}^{(2)} \in \mathscr{S}_{0}\left(\boldsymbol{R}^{n_{2}}\right)$. Thus the theorem follows from Lemma 4.

Next we remove the assumption that $f \in L^{2}$. Let $f \in \mathscr{S}_{*}^{\prime}\left(\boldsymbol{R}^{n}\right)$ and for $\delta=\left(\delta_{1}, \delta_{2}\right) \quad\left(\delta_{i}>0\right)$, set $f^{(\delta)}=f * G_{\delta}$. Then $f^{(\delta)} \in L^{2}$. Let $\psi^{(j, k)}$ be the same as in the statement of Theorem 1 and set

$$
F^{(\delta)}(y, t)=f^{(\delta)} * \phi_{t}(y), \quad K_{j k}^{(\delta)}(y, t)=f^{(\delta)} * \psi_{t}^{(j, k)}(y) .
$$

Then from what we have already proved, it follows that

$$
\left\|N_{a}\left(F^{(\delta)}\right)\right\|_{p} \leqq c \sum_{j, k}\left\|S_{b}\left(K_{j k}^{(\delta)}\right)\right\|_{p} .
$$

Let $\eta$ be as above and set $I^{(\delta)}(y, t)=f^{(\delta)} * \eta_{t} * \eta_{t}(y)$. Then using Lemma 6 and Lemma 8, we have

$$
\left\|S_{b}\left(I^{(\delta)}\right)\right\|_{p} \leqq c\left\|S_{b}(J)\right\|_{p},
$$

where $J(y, t)=f * \eta_{t}(y)$. By (8.2), (8.3) and Lemma 4, we have

$$
\left\|N_{a}\left(F^{(\delta)}\right)\right\|_{p} \leqq c \sum_{j, k}\left\|S_{b}\left(K_{j k}\right)\right\|_{p} .
$$

Letting $\delta_{1} \rightarrow 0, \delta_{2} \rightarrow 0$, we conclude the proof.

9. Preliminaries for the proof of Theorem 2. Recall that

$$
G^{(j, k)}=\left(\partial_{j}^{(1)} G^{(1)}\right) \times\left(\partial_{k}^{(2)} G^{(2)}\right) \text { for } 1 \leqq j \leqq n_{1}, \quad 1 \leqq k \leqq n_{2} \text {; }
$$

and let 


$$
G^{\left(n_{1}+1, k\right)}=\left(\Delta_{1} G^{(1)}\right) \times\left(\partial_{k}^{(2)} G^{(2)}\right), \quad G^{(0, k)}=G^{(1)} \times\left(\partial_{k}^{(2)} G^{(2)}\right) \text { for } k=1, \cdots, n_{2}
$$

(where $\Delta_{i}=\sum_{j=1}^{n_{i}}\left(\partial_{j}^{(i)}\right)^{2}$ is the Laplacian);

$$
\begin{aligned}
& G^{\left(j, n_{2}+1\right)}=\left(\partial_{j}^{(1)} G^{(1)}\right) \times\left(\Delta_{2} G^{(2)}\right), \quad G^{(j, 0)}=\left(\partial_{j}^{(1)} G^{(1)}\right) \times G^{(2)} \quad \text { for } j=1, \cdots, n_{1} ; \\
& G^{(0,0)}=G^{(1)} \times G^{(2)}, \quad G^{\left(0, n_{2}+1\right)}=G^{(1)} \times\left(\Delta_{2} G^{(2)}\right), \\
& G^{\left(n_{1}+1,0\right)}=\left(\Delta_{1} G^{(1)}\right) \times G^{(2)}, \quad G^{\left(n_{1}+1, n_{2}+1\right)}=\left(\Delta_{1} G^{(1)}\right) \times\left(\Delta_{2} G^{(2)}\right) .
\end{aligned}
$$

Let $f\left(\in \mathscr{S}_{*}^{\prime}\left(\boldsymbol{R}^{n}\right)\right)$ be real-valued. Set $K_{j k}(y, t)=f * G_{t}^{(j, k)}, F=K_{00}$. Suppose $\int\{N(F) \wedge 1\}^{2} d x<\infty$. Let

$$
E=\{x: N(F)(x) \leqq 1\},
$$

and set $v(y, t)=\chi_{E} * G_{t}(y), w_{j k}(y, t)=\chi_{C_{E}} * G_{t}^{(j, k)}(y), w=w_{00}$. Note $v+$ $w=1$ and therefore $\partial_{j}^{(i)} v=-\partial_{j}^{(i)} w$. In the proof of Theorem 2, we will use the following equations:

$$
\begin{aligned}
\sum_{j=1}^{n_{1}} T_{t_{1}}^{(1)-1} \partial_{j}^{(1)} T_{t_{1}}^{(1)} K_{j k}=K_{n_{1}+1, k}, & \sum_{k=1}^{n_{2}} T_{t_{2}}^{(2)} \partial_{k}^{-1} \partial_{t_{2}}^{(2)} K_{j k}^{(2)}=K_{j, n_{2}+1}, \\
T_{t_{1}}^{(1)-1} \partial_{j}^{(1)} T_{t_{1}}^{(1)} K_{0 k}=K_{j k}, & T_{t_{2}}^{(2)-1} \partial_{k}^{(2)} T_{t_{2}}^{(2)} K_{j 0}=K_{j k}, \\
t_{1} \frac{\partial}{\partial t_{1}} K_{0 k}=K_{n_{1}+1, k}, & t_{2} \frac{\partial}{\partial t_{2}} K_{j 0}=K_{j, n_{2}+1} .
\end{aligned}
$$

(See [1].) The same equations hold for $w_{j k}$.

It is easy to see the following two lemmas.

LEMma 10. There is a number $\alpha_{1}$ such that $1 / 2<\alpha_{1}<1$ and

$$
\sup \left\{v(y, t):(y, t) \notin \bigcup_{x \in E} \Gamma(x)\right\} \leqq \alpha_{1} \quad\left(\text { if } \boldsymbol{D} \neq \bigcup_{x \in E} \Gamma(x)\right) \text {. }
$$

LEMMA 11. Let $\alpha_{1}$ be the same as in Lemma 10, and let $\alpha_{1}<\alpha_{2}<1$. Set $E^{\prime}=\left\{x \in \boldsymbol{R}^{n}: N(w)(x) \leqq 1-\alpha_{2}\right\}$. Then

$$
\begin{gathered}
\left|\complement E^{\prime}\right| \leqq c|\complement E|, \\
\inf \left\{v(y, t):(y, t) \in \bigcup_{x \in E^{\prime}} \Gamma(x)\right\} \geqq \alpha_{2} .
\end{gathered}
$$

Let $\alpha_{1}, \alpha_{2}$ be as above and put $\alpha_{3}=\left(\alpha_{1}+\alpha_{2}\right) / 2$. Let $r \in C^{\infty}\left(\boldsymbol{R}^{1}\right)$ be such that

$$
\begin{gathered}
r(u)= \begin{cases}1 & \text { if } u \geqq \alpha_{2} \\
0 & \text { if } u \leqq \alpha_{3},\end{cases} \\
\left|r^{\prime}(u)\right|^{2} \leqq \operatorname{cr}(u) \text { for all } u \in R^{1} .
\end{gathered}
$$

Then by Lemma 11 we have

$$
\int_{E^{\prime}} S^{2}\left(\left(\sum_{j=1}^{n_{1}} \sum_{k=1}^{n_{2}} K_{j k}^{2}\right)^{1 / 2}\right) d x \leqq c \int_{D}\left(\sum_{j, k} K_{j k}^{2}\right) r(v) d y \frac{d t}{t_{1} t_{2}} .
$$

For $0<\varepsilon<1 / 2$, set 


$$
I=I^{(\varepsilon)}=\int_{\varepsilon}^{\varepsilon^{-1}} \int_{\varepsilon}^{\varepsilon^{-1}} \int_{R^{n}}\left(\sum_{j=1}^{n_{1}} \sum_{k=1}^{n_{2}} K_{j k}^{2}\right) r(v) d y \frac{d t}{t_{1} t_{2}} .
$$

In order to estimate $I^{(\varepsilon)}$, we need the following result.

LEMMA 12. Let $\phi^{(1)}, \psi^{(1)} \in S\left(\boldsymbol{R}^{n_{1}}\right) ; \phi^{(2)}, \psi^{(2)} \in S\left(\boldsymbol{R}^{n_{2}}\right)$ and suppose $\hat{\phi}^{(1)}(0)=$ $\hat{\psi}^{(2)}(0)=0$. Set $\phi=\phi^{(1)} \times \phi^{(2)}, \psi=\psi^{(1)} \times \psi^{(2)}$. Then if $f \in L^{2}\left(\boldsymbol{R}^{n}\right)$ and $g \in$ $L^{\infty}\left(\boldsymbol{R}^{n}\right)$, we have

$$
\int_{D}\left|f * \dot{\phi}_{t}(y)\right|^{2}\left|g * \psi_{t}(y)\right|^{2} d y \frac{d t}{t_{1} t_{2}} \leqq c\|f\|_{2}^{2}\|g\|_{\infty}^{2} \text {. }
$$

This follows from the argument about a Carleson measure. For this argument see Stein $[16, \S 6]$.

10. Estimate for $I$. We begin the proof of Theorem 2. Set $\bar{d} t=$ $d t /\left(t_{1} t_{2}\right)$. Then by integration by parts we obtain

$$
\begin{aligned}
I & =-\sum_{k} \int K_{0 k} K_{n_{1}+1, k} r(v) d y \bar{d} t+\sum_{j, k} \int K_{0 k} K_{j k} w_{j 0} r^{\prime}(v) d y \bar{d} t \\
& =-I_{1}+I_{2}, \text { say },
\end{aligned}
$$

where (and hereafter) $j$ and $k$ run through $\left\{1, \cdots, n_{1}\right\}$ and $\left\{1, \cdots, n_{2}\right\}$, respectively. For $0<\delta<1 / 4$, we have

$$
\begin{aligned}
\left|I_{2}\right| & \leqq \delta \int\left(\sum_{j, k} K_{j k}^{2}\right) r(v) d y \bar{d} t+c \int\left(\sum_{j, k} K_{0 k}^{2} w_{j 0}^{2}\right) s(v) d y \bar{d} t \\
& =\delta I+c I_{3}, \quad \text { say },
\end{aligned}
$$

where $s$ is a $C^{\infty}$-function on $\boldsymbol{R}^{1}$ such that

$$
\begin{gathered}
s(u)= \begin{cases}1 & \text { if } u \geqq \alpha_{3} \\
0 & \text { if } u \leqq \alpha_{1},\end{cases} \\
\left|s^{\prime}(u)\right|^{2} \leqq \operatorname{cs}(u) \text { for all } u \in \boldsymbol{R}^{1} .
\end{gathered}
$$

(For $\alpha_{1}$ and $\alpha_{3}{ }_{2}$ see $\S 9$.)

Integration by parts gives

$$
\begin{aligned}
I_{1}= & \sum_{k} \int K_{0 k} t_{1}\left(\frac{\partial}{\partial t_{1}} K_{0 k}\right) r(v) d y \bar{d} t \\
= & \sum_{k} \int\left[K_{0 k}^{2}\left(y, \varepsilon^{-1}, t_{2}\right) r\left(v\left(y, \varepsilon^{-1}, t_{2}\right)\right)-K_{0 k}^{2}\left(y, \varepsilon, t_{2}\right) r\left(v\left(y, \varepsilon, t_{2}\right)\right)\right] d y \frac{d t_{2}}{t_{2}} \\
& -\sum_{k} \int t_{1}\left(\frac{\partial}{\partial t_{1}} K_{0 k}\right) K_{0 k} r(v) d y \bar{d} t+\sum_{k} \int K_{0 k}^{2} r^{\prime}(v) w_{n_{1}+1_{0} 0} d y \bar{d} t \\
= & I_{4}-I_{1}+I_{5}, \text { say. }
\end{aligned}
$$

Note that 


$$
I_{s}=-\sum_{j, k} \int 2 K_{0 k} K_{j k} r^{\prime}(v) w_{j 0} d y \bar{d} t+\sum_{j, k} \int K_{0 k}^{2} r^{\prime \prime}(v) w_{j 0}^{2} d y \bar{d} t
$$

Consequently

$$
\left|I_{5}\right| \leqq \delta I+c I_{3}
$$

Thus

$$
I \leqq\left|I_{1}\right|+\left|I_{2}\right| \leqq \frac{1}{2}\left|I_{4}\right|+\frac{1}{2}\left|I_{5}\right|+\left|I_{2}\right| \leqq \frac{1}{2}\left|I_{4}\right|+\frac{3}{2} \delta I+c I_{3} .
$$

This implies that

$$
I \leqq c I_{3}+c\left|I_{4}\right| \text {. }
$$

In the following, we will prove that

$$
\begin{gathered}
I_{3} \leqq c|\complement E E|, \\
\left|I_{4}\right| \leqq c \int\{N(F) \wedge 1\}^{2} d y,
\end{gathered}
$$

uniformly in $\varepsilon$. By Lemma 11 and (9.1), this proves Theorem 2 .

11. Estimate for $I_{3}$. By integration by parts we obtain

$$
\begin{aligned}
I_{3}= & -\sum_{j} \int F K_{0, n_{2}+1} w_{j 0}^{2} s(v) d y \bar{d} t-\sum_{j, k} \int 2 F K_{0 k} w_{j 0} w_{j k} s(v) d y \bar{d} t \\
& +\sum_{j, k} \int F K_{0 k} w_{j 0}^{2} s^{\prime}(v) w_{0 k} d y \bar{d} t \\
= & -J_{1}-J_{2}+J_{3}, \quad \text { say . }
\end{aligned}
$$

We first estimate $J_{1}$. Integration by parts gives

$$
\begin{aligned}
J_{1}= & \sum_{j} \int F t_{2}\left(\frac{\partial}{\partial t_{2}} F\right) w_{j_{0}}^{2} s(v) d y \bar{d} t \\
= & \sum_{j} \int\left[F^{2}\left(y, t_{1}, \varepsilon^{-1}\right) w_{j_{0}}^{2}\left(y, t_{1}, \varepsilon^{-1}\right) s\left(v\left(y, t_{1}, \varepsilon^{-1}\right)\right)\right. \\
& \left.-F^{2}\left(y, t_{1}, \varepsilon\right) w_{j_{0}}^{2}\left(y, t_{1}, \varepsilon\right) s\left(v\left(y, t_{1}, \varepsilon\right)\right)\right] d y \frac{d t_{1}}{t_{1}} \\
& -J_{1}-\sum_{j} \int 2 F^{2} w_{j 0} w_{j, n_{2}+1} s(v) d y \bar{d} t+\sum_{j} \int F^{2} w_{j_{0}}^{2} s^{\prime}(v) w_{0, n_{2}+1} d y \bar{d} t \\
= & L_{1}-J_{1}-L_{2}+L_{3}, \text { say . }
\end{aligned}
$$

By Lemma 10 clearly we have

$$
\left|L_{1}\right| \leqq c \sum_{j} \int\left\{w_{j_{0}}^{2}\left(y, t_{1}, \varepsilon^{-1}\right)+w_{j_{0}}^{2}\left(y, t_{1}, \varepsilon\right)\right\} d y \frac{d t_{1}}{t_{1}}
$$

Using the Plancherel theorem on the right hand side of the above 
inequality, we find $\left|L_{1}\right| \leqq c|\complement E|$.

Next we estimate $L_{2}$.

$$
\begin{aligned}
L_{2}= & 2 \sum_{j} \int F^{2} w_{j 0}\left(\sum_{k=1}^{n_{2}} T_{t_{2}}^{(2)-1} \partial_{k}^{(2)} T_{t_{2}}^{(2)} w_{j k}\right) s(v) d y \bar{d} t \\
= & -\sum_{j, k} 4 \int F K_{0 k} w_{j 0} w_{j k} s(v) d y \bar{d} t-\sum_{j, k} 2 \int F^{2} w_{j k}^{2} s(v) d y \bar{d} t \\
& +\sum_{j, k} 2 \int F^{2} w_{j 0} w_{j k} w_{0 k} s^{\prime}(v) d y \bar{d} t \\
= & -M_{1}-M_{2}+M_{3}, \text { say . }
\end{aligned}
$$

It is easy to see that

$$
\left|M_{1}\right| \leqq \delta I_{3}+c \sum_{j, k} \int w_{j_{k}}^{2} d y \bar{d} t \leqq \delta I_{3}+c|\complement E|
$$

and

$$
\left|M_{2}\right| \leqq c|\complement E|
$$

By Lemma 12, we have

$$
\left|M_{3}\right| \leqq c \sum_{j, k}\left(\int w_{j_{0}}^{2} w_{0 k}^{2} d y \bar{d} t\right)^{1 / 2}\left(\int w_{j k}^{2} d y \bar{d} t\right)^{1 / 2} \leqq c|\complement E| .
$$

Thus

$$
\left|L_{2}\right| \leqq\left|M_{1}\right|+\left|M_{2}\right|+\left|M_{3}\right| \leqq \delta I_{3}+c|\complement E| \text {. }
$$

In order to estimate $L_{3}$, note that

$$
L_{3}=\sum_{j} \int F^{2} w_{j 0}^{2} s^{\prime}(v)\left(\sum_{k=1}^{n_{2}} T_{t_{2}}^{(2)-1} \partial_{k}^{(2)} T_{t_{2}}^{(2)} w_{0 k}\right) d y \bar{d} t .
$$

Thus by integration by parts we have

$$
\begin{aligned}
L_{3}= & -\sum_{j, k} 2 \int F K_{0 k} w_{j 0}^{2} s^{\prime}(v) w_{0 k} d y \bar{d} t-\sum_{j, k} 2 \int F^{2} w_{j 0} w_{j k} s^{\prime}(v) w_{0 k} d y \bar{d} t \\
& +\sum_{j, k} \int F^{2} w_{j 0}^{2} s^{\prime \prime}(v) w_{0 k}^{2} d y \bar{d} t \\
= & -M_{4}-M_{5}+M_{6}, \text { say . }
\end{aligned}
$$

We estimate $M_{4}, M_{5}, M_{6}$ as follows.

$$
\begin{aligned}
& \left|M_{4}\right| \leqq \delta I_{3}+\sum_{j, k} c \int w_{j_{0}}^{2} w_{0 k}^{2} d y \bar{d} t \leqq \delta I_{3}+c|\complement E|, \\
& \left|M_{b}\right| \leqq \sum_{j, k} c\left(\int w_{j_{0}}^{2} w_{0 k}^{2} d y \bar{d} t\right)^{1 / 2}\left(\int w_{j_{k}}^{2} d y \bar{d} t\right)^{1 / 2} \leqq c|\complement E| \\
& \left|M_{6}\right| \leqq \sum_{j, k} c \int w_{j_{0}}^{2} w_{0 k}^{2} d y \bar{d} t \leqq c|\complement E|
\end{aligned}
$$


This implies that

$$
\left|L_{3}\right| \leqq\left|M_{4}\right|+\left|M_{8}\right|+\left|M_{6}\right| \leqq \delta I_{3}+c|\complement E| .
$$

Therefore

$$
\left|J_{1}\right| \leqq \frac{1}{2}\left|L_{1}\right|+\frac{1}{2}\left|L_{2}\right|+\frac{1}{2}\left|L_{3}\right| \leqq \delta I_{3}+c|\complement| C \mid .
$$

It is easy to obtain the following estimates for $J_{2}$ and $J_{3}$ :

$$
\begin{aligned}
& \left|J_{2}\right| \leqq \delta I_{3}+\sum_{j, k} c \int w_{j_{k}}^{2} d y \bar{d} t \leqq \delta I_{3}+c|\complement E| \\
& \left|J_{3}\right| \leqq \delta I_{3}+\sum_{j, k} c \int w_{j_{0}}^{2} w_{0 k}^{2} d y \bar{d} t \leqq \delta I_{3}+c|\complement E|
\end{aligned}
$$

Consequently

$$
\left|I_{3}\right| \leqq\left|J_{1}\right|+\left|J_{2}\right|+\left|J_{3}\right| \leqq 3 \delta I_{3}+c|\complement E|
$$

Thus

which proves (10.1).

$$
I_{3} \leqq c|\complement E|
$$

12. Estimate for $I_{4}$. Set

$$
I_{4}^{(1)}=\sum_{k} \int K_{0 k}^{2}\left(y, \varepsilon, t_{2}\right) r\left(v\left(y, \varepsilon, t_{2}\right)\right) d y \frac{d t_{2}}{t_{2}} .
$$

Then by integration by parts we have

$$
\begin{aligned}
I_{4}^{(1)} & =\sum_{k} \int\left(T_{t_{2}}^{(2)-1} \partial_{k}^{(2)} T_{t_{2}}^{(2)} F\right) K_{0 k} r(v) d y \frac{d t_{2}}{t_{2}} \\
& =-\int F K_{0, n_{2}+1} r(v) d y \frac{d t_{2}}{t_{2}}+\sum_{k} \int F K_{0 k} r^{\prime}(v) w_{0 k} d y \frac{d t_{2}}{t_{2}} \\
& =-J_{4}+J_{5}, \quad \text { say . }
\end{aligned}
$$

We estimate $J_{4}$. Integration by parts gives

$$
\begin{aligned}
J_{4}= & \int F \frac{\partial}{\partial t_{2}} F r(v) d y d t_{2} \\
= & \int\left[F^{2}\left(y, \varepsilon, \varepsilon^{-1}\right) r\left(v\left(y, \varepsilon, \varepsilon^{-1}\right)\right)-F^{2}(y, \varepsilon, \varepsilon) r(v(y, \varepsilon, \varepsilon))\right] d y-J_{4} \\
& +\int F^{2} r^{\prime}(v) w_{0, n_{2}+1} d y \frac{d t_{2}}{t_{2}} \\
= & L_{4}-J_{4}+L_{5}, \quad \text { say . }
\end{aligned}
$$

Clearly 


$$
\left|L_{4}\right| \leqq c \int\{N(F) \wedge 1\}^{2} d y .
$$

Next we estimate $L_{5}$.

$$
\begin{aligned}
L_{8} & =\int F^{2} r^{\prime}(v) \sum_{k=1}^{n_{2}}\left(T_{t_{2}}^{(2)-1} \partial_{k}^{(2)} T_{t_{2}}^{(2)} w_{0 k}\right) d y \frac{d t_{2}}{t_{2}} \\
& =-\sum_{k} 2 \int F K_{0 k} w_{0 k} r^{\prime}(v) d y \frac{d t_{2}}{t_{2}}+\sum_{k} \int F^{2} w_{0 k}^{2} r^{\prime \prime}(v) d y \frac{d t_{2}}{t_{2}} \\
& =-M_{7}+M_{8}, \quad \text { say . }
\end{aligned}
$$

It is easy to see that

$$
\begin{aligned}
& \left|M_{7}\right| \leqq \delta I_{4}^{(1)}+c \sum_{k} \int w_{0 k}^{2} d y \frac{d t_{2}}{t_{2}} \leqq \delta I_{4}^{(1)}+c|\complement E|, \\
& \left|M_{8}\right| \leqq c \sum_{k} \int w_{0 k}^{2} d y \frac{d t_{2}}{t_{2}} \leqq c|\complement E| .
\end{aligned}
$$

This implies that

$$
\left|L_{5}\right| \leqq\left|M_{7}\right|+\left|M_{8}\right| \leqq \delta I_{4}^{(1)}+c|\complement E| .
$$

Consequently

$$
\left|J_{4}\right| \leqq \frac{1}{2}\left|L_{4}\right|+\frac{1}{2}\left|L_{b}\right| \leqq \delta I_{4}^{(1)}+c \int\{N(F) \wedge 1\}^{2} d y .
$$

Since

$$
\left|J_{5}\right| \leqq \delta I_{4}^{(1)}+c \sum_{k} \int w_{0 k}^{2} d y \frac{d t_{2}}{t_{2}} \leqq \delta I_{4}^{(1)}+c|\mathcal{C} E|
$$

we have

$$
I_{4}^{(1)} \leqq\left|J_{4}\right|+\left|J_{5}\right| \leqq 2 \delta I_{4}^{(1)}+c \int\{N(F) \wedge 1\}^{2} d y
$$

Thus

$$
I_{4}^{(1)} \leqq c \int\{N(F) \wedge 1\}^{2} d y
$$

If we set

$$
I_{4}^{(2)}=\sum_{k} \int K_{0 k}^{2}\left(y, \varepsilon^{-1}, t_{2}\right) r\left(v\left(y, \varepsilon^{-1}, t_{2}\right)\right) d y \frac{d t_{2}}{t_{2}},
$$

then in the same way as above, we obtain

$$
I_{i}^{(2)} \leqq c \int\{N(F) \wedge 1\}^{2} d y .
$$


Thus

$$
\left|I_{4}\right| \leqq I_{4}^{(1)}+I_{4}^{(2)} \leqq c \int\{N(F) \wedge 1\}^{2} d y,
$$

which proves (10.2).

13. Proof of Theorem 3. Let $K^{(i)}$ be the same as in Theorem 3 and suppose that $P_{i}$ is diagonal. Let $\zeta_{0} \in C^{\infty}\left(\boldsymbol{R}^{1}\right)$ be such that

$$
\zeta_{0} \geqq 0, \quad \zeta_{0}(u)=\left\{\begin{array}{lll}
1 & \text { if } & u \leqq 1 \\
0 & \text { if } & u \geqq 2 .
\end{array}\right.
$$

Set

$$
\begin{aligned}
\bar{K}^{(i)}\left(x^{(i)}\right) & =K^{(i)}\left(x^{(i)}\right) \zeta_{0}\left(a \rho^{(i)}\left(x^{(i)}\right)\right) \quad(a>0), \\
\bar{K} & =\bar{K}^{(1)} \times \bar{K}^{(2)}, \\
\bar{K}^{(i), \delta}\left(x^{(i)}\right) & =\bar{K}^{(i)}\left(x^{(i)}\right)\left(1-\zeta_{0}\left(\delta^{-1} \rho^{(i)}\left(x^{(i)}\right)\right)\right) \quad(\delta>0), \\
\bar{K}^{(\delta)} & =\bar{K}^{(1), \delta} \times \bar{K}^{(2), \delta} \\
\bar{K}_{\varepsilon_{i}}^{(i)}\left(x^{(i)}\right) & =\bar{K}^{(i)}\left(x^{(i)}\right)\left(1-\chi_{[0,1]}\left(\varepsilon_{i}^{-1} \rho^{(i)}\left(x^{(i)}\right)\right)\right), \\
\bar{K}_{\varepsilon} & =\bar{K}_{\varepsilon_{1}}^{(1)} \times \bar{K}_{\varepsilon_{2}}^{(2)} \quad\left(\varepsilon=\left(\varepsilon_{1}, \varepsilon_{2}\right), \varepsilon_{i}>0\right) .
\end{aligned}
$$

On account of a theorem of Stein [15], which generalizes an indirect method of Kolmogoroff [12], Theorem 3 follows from the next lemma. (The constant $a$ in the definition of $\bar{K}^{(i)}$ will be determined depending on the sets $A$ and $B$. See [9, p. 138].)

LEMMA 13. If $f$ is a function on $\boldsymbol{R}^{n}$ with compact support and satisfies

$$
\begin{aligned}
& \int|f| \log (2+|f|) d x<\infty, \\
& \int f\left(x^{(1)}, x^{(2)}\right) d x^{(2)}=0 \text { for all } x^{(1)} \in \boldsymbol{R}^{n_{1}}, \\
& \int f\left(x^{(1)}, x^{(2)}\right) d x^{(1)}=0 \text { for all } x^{(2)} \in \boldsymbol{R}^{n_{2}},
\end{aligned}
$$

then we have $\sup _{\varepsilon}\left|f * \bar{K}_{\varepsilon}(x)\right|<\infty$ for almost every $x$.

We begin the proof of Lemma 13. Let $\phi^{(i)} \in \mathscr{S}_{1}\left(\boldsymbol{R}^{n_{i}}\right)$ be such that $\phi^{(i)} \geqq 0, \quad \operatorname{supp} \phi^{(i)} \subset\left\{x^{(i)}: \rho^{(i)}\left(x^{(i)}\right) \leqq 1\right\}$ and set $\phi=\phi^{(1)} \times \phi^{(2)}$. To estimate $f * \bar{K}_{\varepsilon}$, we use the following lemmas.

LEMMA 14. There is $\sigma_{i}>0$ such that

$\left|\bar{K}_{\varepsilon_{i}}^{(i)}\left(x^{(i)}\right)-\bar{K}^{(i), \delta} * \phi_{\varepsilon_{i}}^{(i)}\left(x^{(i)}\right)\right| \leqq c \varepsilon_{i}^{-\gamma_{i}}\left(1+\varepsilon_{i}^{-1} \rho^{(i)}\left(x^{(i)}\right)\right)^{-\gamma_{i}-\sigma_{i}}$ if $2 \delta<\varepsilon_{i}$.

Lemma 15. Let $\eta^{(i)} \in \mathscr{S}\left(\boldsymbol{R}^{n_{i}}\right)$ and $\operatorname{supp} \eta^{(i)} \subset\left\{x^{(i)}: \rho^{(i)}\left(x^{(i)}\right) \leqq 1\right\}$. Given 
$L>0$, there exists $M>0$ such that if

$$
\int \eta^{(i)}\left(x^{(i)}\right) x^{(i) \alpha} d x^{(i)}=0
$$

for all multi-indices $\alpha$ satisfying $|\alpha| \leqq M$, then we have

$$
\left|\int t_{i}^{-\gamma_{i}} \bar{K}^{(i), \delta}\left(A_{t_{i}}^{(i)-1}\left(x^{(i)}-y^{(i)}\right)\right) \eta^{(i)}\left(y^{(i)}\right) d y^{(i)}\right| \leqq c\left(1+\rho^{(i)}\left(x^{(i)}\right)\right)^{-L},
$$

where $c$ is independent of $t_{i}$ and $\delta$.

When $g$ is a function on $\boldsymbol{R}^{n}$, set

$$
\begin{aligned}
& M^{(1)} g\left(x^{(1)}, x^{(2)}\right)=\sup _{t_{1}>0} t_{1}^{-\gamma_{1}} \int_{B_{1}\left(x^{(1)}, t_{1}\right)}\left|g\left(y^{(1)}, x^{(2)}\right)\right| d y^{(1)}, \\
& M^{(2)} g\left(x^{(1)}, x^{(2)}\right)=\sup _{t_{2}>0} t_{2}^{-\gamma_{2}} \int_{B_{2}\left(x^{(2)}, t_{2}\right)}\left|g\left(x^{(1)}, y^{(2)}\right)\right| d y^{(2),}
\end{aligned}
$$

where $B_{i}\left(x^{(i)}, t_{i}\right)=\left\{y^{(i)}: \rho^{(i)}\left(x^{(i)}-y^{(i)}\right)<t_{i}\right\}$. Then if $f$ satisfies the assumptions of Lemma 13, by arguing as in [9] and by using Lemma 14 we have

$$
\begin{aligned}
\sup _{\varepsilon}\left|f * \bar{K}_{\varepsilon}\right| \leqq & c M^{(2)}\left(\sup _{\varepsilon_{1}}\left|f *_{(1)} \bar{K}_{\varepsilon_{1}}^{(1)}\right|\right)+c M^{(1)}\left(\sup _{\varepsilon_{2}}\left|f *_{(2)} \bar{K}_{\varepsilon_{2}}^{(2)}\right|\right) \\
& +c M^{(1)} M^{(2)} f+\liminf _{\delta \rightarrow 0}\left(\sup _{\varepsilon}\left|f * \bar{K}^{(\delta)} * \dot{\phi}_{\varepsilon}\right|\right),
\end{aligned}
$$

where the symbol $*_{(i)}$ denotes the operation of convolution in $\boldsymbol{R}^{n_{i}}$. It is clear that $M^{(1)} M^{(2)} f<\infty$ a.e. since $\int|f| \log (2+|f|) d x<\infty$.

We next note that if $F(y, t)=f * \phi_{t}(y)$, then $\int N^{p_{0}}(F) d x<\infty$ for some $p_{0}$ with $0<p_{0}<1$. (This follows from a direct estimate for $N(F)$.) Thus to prove $\liminf f_{\delta \rightarrow 0}\left(\sup _{\varepsilon}\left|f * \bar{K}^{(\delta)} * \phi_{\varepsilon}\right|\right)<\infty$ a.e., it is sufficient to show that

$$
\sup _{\delta} \int_{\varepsilon} \sup _{\varepsilon}\left|f * \bar{K}^{(\hat{\delta})} * \phi_{\varepsilon}\right|^{p_{0}} d x \leqq c \int N^{p_{0}}(F) d x .
$$

Now we prove (13.2). Let $\eta^{(i)} \in \mathscr{S}\left(\boldsymbol{R}^{n_{i}}\right)$ and supp $\eta^{(i)} \subset\left\{x^{(i)}: \rho^{(i)}\left(x^{(i)}\right) \leqq\right.$ 1). Suppose also that $\eta^{(i)}$ satisfies the condition (13.1) for sufficiently large $M$ and the condition:

$$
\sup _{t_{i}>0}\left|\hat{\eta}^{(i)}\left(A_{t_{i}}^{(i) *} \xi^{(i)}\right)\right|>0 \quad\left(\xi^{(i)} \neq 0\right) .
$$

Set $H^{(\delta)}(y, t)=f * \bar{K}^{(\delta)} * \eta_{t} * \eta_{t}(y) \quad\left(\eta=\eta^{(1)} \times \eta^{(2)}\right), J(y, t)=f * \eta_{t}(y)$. Then by Theorem 1 we have

$$
\int \sup _{\varepsilon}\left|f * \bar{K}^{(\delta)} * \phi_{\varepsilon}\right|^{p_{0}} d x \leqq c \int S^{p_{0}}\left(H^{(\delta)}\right) d x .
$$

Using Lemma 6, Lemma 8 and Lemma 15 (for sufficiently large $L$ ), we 
obtain

$$
\int S^{p_{0}}\left(H^{(\delta)}\right) d x \leqq c \int S^{p_{0}}(J) d x,
$$

where $c$ is independent of $\delta$. By the corollary to Theorem 2, we have

$$
\int S^{p_{0}}(J) d x \leqq c \int N^{p_{0}}(\boldsymbol{F}) d x
$$

Combining the above inequalities, we obtain (13.2).

To prove $M^{(2)}\left(\sup _{\varepsilon_{1}}\left|f *_{(1)} \bar{K}_{\varepsilon_{1}}^{(1)}\right|\right)<\infty$ a.e., note that

$$
M^{(2)}\left(\sup _{\varepsilon_{1}}\left|f *_{(1)} \bar{K}_{\varepsilon_{1}}^{(1)}\right|\right) \leqq c M^{(2)} M^{(1)} f+c M^{(2)}(\Omega),
$$

where $\Omega=\liminf _{\delta \rightarrow 0}\left(\sup _{\varepsilon_{1}}\left|f *_{(1)} \bar{K}^{(1), \delta} *_{(1)} \phi_{\varepsilon_{1}}^{(1)}\right|\right)$ (this follows from Lemma 14). Since $M^{(2)} M^{(1)} f$ is finite almost everywhere, we only have to prove $M^{(2)}(\Omega)<\infty$ a.e. Let $V$ be a compact set in $\boldsymbol{R}^{n}$. Then since $M^{(2)}$ is of weak type $(1,1)$, we have

$$
\int_{V}\left\{M^{(2)}(\Omega)\right\}^{q} d x \leqq c+c \int_{W} \Omega d x \quad(0<q<1)
$$

for some compact set $W$ in $\boldsymbol{R}^{n}$. If $F^{(1)}\left(y^{(1)}, t_{1}\right)=\left(\phi_{t_{1}}^{(1)} *_{(1)} f\left(\cdot, x^{(2)}\right)\right)\left(y^{(1)}\right)$ for fixed $x^{(2)}$, then we can prove directly

$$
\int N^{(1)}\left(F^{(1)}\right) d x^{(1)} \leqq c+c \int\left|f\left(x^{(1)}, x^{(2)}\right)\right| \log \left(2+\left|f\left(x^{(1)}, x^{(2)}\right)\right|\right) d x^{(1)} .
$$

Thus the finiteness of the integral on the right hand side of (13.3) follows from the equivalence of $S^{(1)}$ and $N^{(1)}$ if we argue as in the proof of (13.2). This proves the almost everywhere finiteness of $M^{(2)}(\Omega)$, which completes the proof of the fact that $M^{(2)}\left(\sup _{\varepsilon_{1}}\left|f *_{(1)} \bar{K}_{\varepsilon_{1}}^{(1)}\right|\right)<\infty$ a.e. The almost everywhere finiteness of $M^{(1)}\left(\sup _{\varepsilon_{2}}\left|f *_{(2)} \bar{K}_{\varepsilon_{2}}^{(2)}\right|\right)$ is proved similarly. This completes the proof of Lemma 13.

\section{REFERENCES}

[1] A. P. Calderón and A. Torchinsky, Parabolic maximal functions associated with a distribution, Advances in Math. 16 (1975), 1-64.

[2] A.P. CALDERÓN AND A. TORCHINSKY, Parabolic maximal functions associated with a distribution, II, Advances in Math. 24 (1977), 101-171.

[3] L. Carleson, Two remarks on $H^{1}$ and BMO, Advances in Math. 22 (1976), 269-277.

[4] R. R. Coifman aNd B. Dahlberg, Singular integral characterization of nonisotropic $H^{p}$ spaces and the F. and M. Riesz theorem, Proc. Symp. in pure Math. 35 part 1 (1979), 231-234.

[5] R.R. Coifman and G. Weiss, Extensions of Hardy spaces and their use in analysis, Bull. Amer. Math. Soc. 83 (1977), 569-645.

[6] E. B. FABES AND N.M. RIviÈRE, Singular integrals with mixed homogeneity, Studia Math. 27 (1966), 19-38. 
[7] C. Fefferman, Estimates for double Hilbert transforms, Studia Math. 44 (1972), 1-15.

[8] C. Feffrerman and E. M. Stein, $H^{p}$ spaces of several variables, Acta Math. 129 (1972), 138-193.

[9] R. FeffFerman and E. M. Stein, Singular integrals on product spaces, Advances in Math. 45 (1982), 117-143.

[10] R.F. GUNDY, Inégalités pour martingales à un et deux indices: L'espaces $H^{p}$, Lecture Notes in Math. 774, Springer-Verlag, Berlin, Heidelberg and New York, 1980 (pp. 251-334).

[11] R.F. Gundy ANd E. M. Stein, $H^{p}$ theory for the poly-disc, Proc. Natl. Acad. Sci. USA 76 (1979), 1026-1029.

[12] A. KolmogorofF, Sur les fonctions harmoniques conjuguées et les séries de Fourier, Fund. Math. 7 (1925), 23-28.

[13] M. P. Maldiavin and P. Malliavin, Intégrales de Lusin-Calderón pour les fonctions biharmoniques, Bull. Sci. Math. 101 (1977), 357-384.

[14] N. M. RIVİ̀RE, Singular integrals and multiplier operators, Ark. Mat. 9 (1971), 243-278.

[15] E. M. StEIN, On limits of sequences of operators, Ann. of Math. 74 (1961), 140-170.

[16] E. M. Stein, A variant of the area integral, Bull. Sci. Math. 103 (1979), 449-461.

[17] E. M. Stein and G. WeIss, Introduction to Fourier analysis on Euclidean spaces, Princeton Univ. Press, 1971.

Mathematical Institute

TôHOKU UNIVERSITY

SENDAI, 980

JAPAN 
